\title{
Publicación científica: Un debe ser de las instituciones de educación superior
}

\author{
Scientific publication: A must be of institutions of higher education
}

Las instituciones de educación superior (IES) además de la formación de profesionales, tienen como misión la generación y difusión del conocimiento. La generación de conocimiento se logra mediante la investigación y la difusión a través de las publicaciones.

La palabra publicar proviene del latín publicare que significa "hacer público". El diccionario de la Real Academia Española define publicar como "difundir por medio de la imprenta o de otro procedimiento cualquiera un escrito, una estampa, etc.", y publicación como la "acción y efecto de publicar" y como "escrito impreso, como un libro, una revista, un periódico, etc., que ha sido publicado" (1); ambas acepciones del término publicación, aplican como funciones de las IES.

El conocimiento científico necesita ser comunicado para favorecer el progreso de la ciencia, pero también para evitar esfuerzos duplicados y gastos innecesarios. La publicación científica se puede clasificar en: primaria, secundaria, terciaria y cuaternaria. La publicación primaria es la que publica resultados originales de investigación; la secundaria agrupa y sintetiza la información disponible, por ejemplo revisión de temas y revisiones sistemáticas; la terciaria publica información que ha dejado de ser controversia, ejemplo los libros de texto, y la cuaternaria, es la información de divulgación hacia la comunidad no científica escrita por los propios investigadores (2).

En base a esta clasificación se generan varios tipos de publicaciones. Las revistas científicas son las publicaciones que contienen resultados de investigación, pero también publican otros tipos de contribuciones específicas como editoriales, revisiones de temas, revisiones sistemáticas, opiniones, por mencionar algunos. Los libros de texto, manuales, handbooks, enciclopedias, reportes técnicos, entre otros, son productos de uno o varios autores que tratan un tema general o específico, con información que ha dejado de ser controversia (3). Además, los gobiernos, académicos, empresas e industrias producen material publicado como reportes, posters científicos, presentaciones, folletos, etc., que no está controlado por un editor comercial; esto es lo que algunos llaman "literatura gris" (3).

El uso de Internet ha creado nuevos tipos de documentos y nuevas formas de trabajar con los datos e información. $\mathrm{Al}$ inicio la publicación electrónica representaba la contraparte de los documentos impresos, ahora ha evolucionado en nuevos tipos de material como blogs, wikis, páginas personales, listas de discusión, data vinculada y archivos pre y pos impresos, por mencionar algunos (3). A esto se suma el aumento del interés del periodismo en la difusión del conocimiento científico, en especial los relacionados con la salud, a través de los diarios, sus suplementos y sus portales en Internet.

Si bien las IES declaran en su misión la formación profesional, la investigación, la difusión del conocimiento y la vinculación con el entorno, no las realizan en la misma magnitud y dedicación, lo que hace que las IES no sean iguales. Existen las que realizan las tres funciones, las que realizan básicamente formación profesional, las que se dedican principalmente a investigación, y las que actúan según las necesidades del entorno. Por ello, es esperable que las IES que fomentan y realizan investigación, también generen publicaciones científicas primarias, dado que "la filosofía de la ciencia se basa en la premisa que las investigaciones se tienen que publicar" (4), y por que "es una responsabilidad ética comunicar los resultados de una investigación" (5). 
Pero, en materia de publicaciones ¿qué se espera de las IES que sólo se dedican a la formación profesional? Se espera que la producción sea en publicaciones secundarias y terciarias, en otras palabras, revisiones de temas en revistas científicas o libros de texto, manuales, reportes técnicos, etc., que puedan ser utilizados por los estudiantes y egresados en su formación profesional y formación continua.

En los países desarrollados, el docente tiene claro que debe generar publicaciones durante su vida académica, por ello alrededor de $85 \%$ de la producción científica mundial es realizada por el grupo de países desarrollados. Además, muchas IES cuentan con editoriales universitarias con gran producción de libros de texto, manuales, handbooks y revistas científicas.

En Latinoamérica en cambio y en especial en nuestro país, en muchas universidades no se realiza investigación y los docentes no tienen la cultura de escribir ni publicar, por ello la producción científica, salvo honrosas excepciones, es pobre. De esta manera, el comportamiento de muchas de las IES en Perú es de consumir información de otros y no de producir información. Alberto Hurtado en su artículo Oportunidad de Investigación Médica en los Hospitales (6), publicado en 1955 mencionó: "La educación no puede ser óptima cuando es conducida entre cauces pasivos de imitación y aplicación de conocimientos provenientes en su totalidad de la experiencia ajena”.

Por todo lo mencionado queda claro que al menos la publicación científica es un debe ser de las IES. Las universidades y otras IES, considerando sus características propias tienen la obligación de contribuir al desarrollo de la sociedad, generando conocimiento y en la formación profesional, pero utilizando experiencia propia.

Juan Miyahira ${ }^{1, a}$

1 Facultad de Medicina Alberto Hurtado. Universidad Peruana Cayetano Heredia. Lima, Perú.

a Profesor Principal 